\title{
Residue on Lateral Sulci
}

National Cancer Institute

\section{Source}

National Cancer Institute. Residue on Lateral Sulci. NCI Thesaurus. Code C127218.

A finding of oral residue remaining on lateral sulci after an individual swallows. 